Acta Crystallographica Section E

Structure Reports

Online

ISSN 1600-5368
William Clegg ${ }^{\mathrm{a} *}$ and David G. Watson ${ }^{b}$

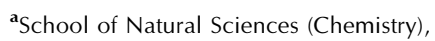
University of Newcastle, Newcastle upon Tyne NE1 7RU, England, and ${ }^{\mathbf{b}}$ Cambridge Crystallographic Data Centre, 12 Union Road, Cambridge CB2 1EZ, England

Online 24 December 2004

\section{Structure Reports Online: more than $100 \%$ growth from 2001}

The year 2004 has seen another sustained period of growth for Acta Crystallographica Section E: Structure Reports Online. The total number of papers published was 1808 , covering 4673 pages in PDF format. This is considerably more than double the size of the first year's journal, with 800 papers and almost 2000 pages in 2001. The December 2004 issue was the largest ever, with 232 papers, which would represent over 2500 per year if continued at this level. The numbers of papers published in each category were: inorganic 57; metal-organic 743; organic 1003; addenda and errata 5.

Despite this rapid growth in volume, the average time taken from receipt to publication remains below one month. This is due in no small measure to the dedication and hard work of the IUCr editorial staff responsible for the handling of submissions, generation of proofs, and conversion of manuscripts to their final published form, and we particularly thank Peter Strickland as Managing Editor, together with Gillian Holmes and Sean Conway, who have special responsibility for Section E.

To cope with the increasing number of papers submitted to the journal we have appointed a number of new Co-editors. We welcome Professor Ray Butcher (Howard University, Washington DC, USA), Dr Lars Eriksson (Stockholm University, Sweden), Dr Richard Gilardi (Naval Research Laboratory, Washington DC, USA), Professor Hiroyuki Ishida (Okayama University, Japan), Dr Biserka Kojić-Prodić (Ruder Boskovic Institute, Zagreb, Croatia), Dr Christian Näther (University of Kiel, Germany), Professor Corrado Rizzoli (University of Parma, Italy) and Professor Jim Simpson (University of Otago, New Zealand). During the year we lost two Co-editors. Professor Marilyn Olmstead (University of California, Davis, USA) gave up her editorial role, at least for a while, through pressure of other commitments; we thank her for her contribution to the journal in its first years, and hope she will be able to take up some editorial work again in the future. Section $E$ and other activities of the IUCr also suffered considerably by the death of Professor Mario Nardelli (University of Parma, Italy). All the Co-editors, of whom we now have 30, deserve our deep thanks and praise for their enormous efforts and enthusiasm.

The process for submitting manuscripts to Section $E$ is currently undergoing substantial development and it is expected that, within about three months, all material for a submission, including structure factors, graphics and copyright agreements, as well as the CIF itself, will be uploaded through the journal web site; this will be a simpler process than the current one of uploading a CIF and then providing other material in response to an acknowledgement of receipt. Notes for Authors will be modified to reflect these changes as well as some others, and the new version of these Notes will be available in due course at http:// journals.iucr.org/e/journalhomepage.html under 'Author services'.

The submission process now automatically returns manuscripts to authors for further revision or the incorporation of an appropriate validation report form (VRF) if any level A alerts are generated by the checking procedures. Authors are reminded that they are required to use checkCIF prior to submission, to ensure that significant problems are identified and addressed. The journal's web site also provides other information and support for authors, including links to 
software, such as enCIFer from the Cambridge Crystallographic Data Centre and printCIF for Word, a Microsoft Word template from the IUCr.

A report on Structure Reports Online will be presented at the Open Meeting of the IUCr Journals Commission during the International Crystallography Congress in Florence in August 2005. Authors and readers are encouraged to attend, and to discuss any topics of interest with editorial staff during the Congress or at other times.

We expect 2005 to see further growth, and we are constantly seeking to streamline the editorial and manuscript handling processes to maintain high standards and rapid publication. We thank our authors, subscribers and readers for their interest and support. 